\title{
The marketing strategy to enhance new book reading
}

\author{
Chi-Lung Lee \\ Director of Information Center \\ The Affiliated Senior High School of National Taiwan Normal University \\ Taiwan, ROC
}

\begin{abstract}
This paper tries to use marketing strategy to change school teacher and student's stereotype perception of the library, so as to effectively improve new book loan, further cultivate good reading aura for the school, and build a more perfect reading environment for students.
\end{abstract}

\section{Introduction}

Cultivation of good reading aura has been one of the crucial tasks of school libraries. Students can greatly benefit from the good reading habit in their future lives if they can develop it during their school attending years. The school statistics show that less than $20 \%$ of new books were borrowed within one year after their arrival. That is about $80 \%$ of new books stayed completely un-borrowed in their first year in the library. Pretty soon, the new books would turn out to be old ones, and their rate to be borrowed would be increasingly slipping down.

Under such circumstances, the school library has launched a "New book lending promotion program" activity to send new arrival books to the locations in the routes having to be taken by school teachers and students in an attempt to enhance new book loan. In addition to displaying new books, a new book loan service by using information technology to directly access the library's automatic system through notebooks and wireless network is also provided on the spot.

New books may be more attractive than old ones for school teachers and students were greatly moved by such kind of proactive and aggressive service, so the promotion received very good response. More than $80 \%$ of new books purchased by the library were borrowed away by teachers and students in the two-day activity. Some teachers or students who had never visited the school library started to borrow the books through the "New book lending promotion program", and in the end, they all stepped into the library to return the books in which the activity's objective to promote the library was skillfully achieved.

Hence, this paper tries to use such proactive and aggressive way to change school teacher and student's stereotype perception of the library, so as to effectively improve new books loan, further cultivate good reading aura for the school, and build a more perfect reading environment for students. 


\section{The process of the new book lending promotion}

\section{Background}

To review one-year new books loaning situation: It was found that less than $20 \%$ of new books were borrowed within one year after their arrival. Even though the library has a "new book special zone" available to present those new books, the books loaning effect was less than expected. We have about 1200 new books per year, but only about 200 books were borrowed by teachers or students.

To formulate a strategy with proactive services and aggressive marketing: The toolow new book borrowing rate is a waste of resources which should be improved. Thus, with an aggressive attitude to provide proactive services, a "New book lending promotion program" activity was brought out targeting the locations in the routes taken by school teachers and students and in conjunction with information technology to offer on-site new book loan service.

\section{The process of new book lending promotion program}

\section{Step1: To select new books}

The latest arrival books were sorted into volumes and displayed in the activity spots. A total of 303 volumes of books were displayed in the "New book lending promotion program" activity, in which 129 volumes were the new books purchased by the library while 174 volumes were the ones given by the central office of Ministry of Education (MOE).

\section{Step2: Timing of the activity}

The period between the first and second mid-term examinations was selected for the "New book lending promotion program" activity in the hope of raising student's participation and enhancing the promotion effect.

\section{Step3: To review the activity effect}

After the end of the activity, it was viewed by a way of oral conversation trying to understand how school teachers and students felt about this activity. 
Some activity pictures :

Picture 1: The "New book lending promotion program" is running.

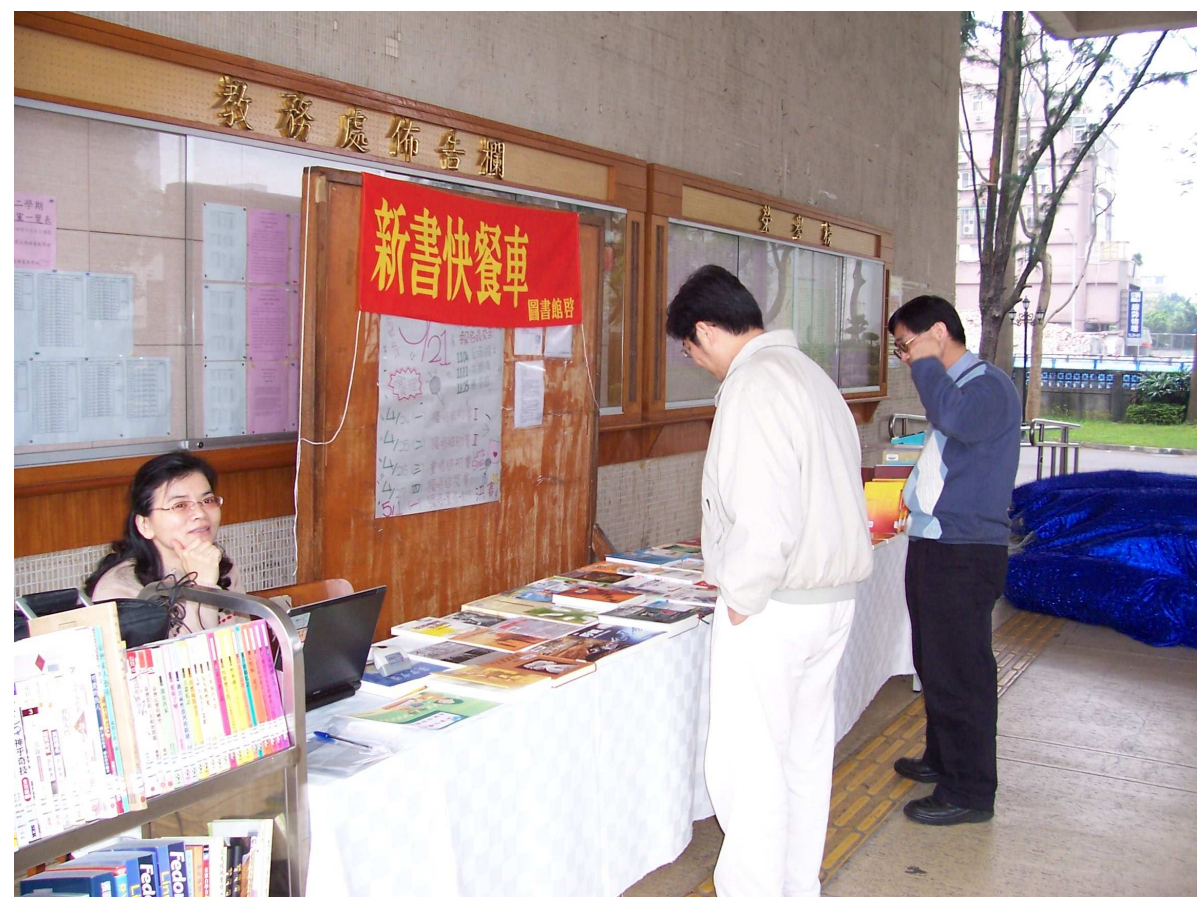

Picture 2: Our new book lending desk is located beside restaurant. If students go to restaurant then they will probably borrow some books.

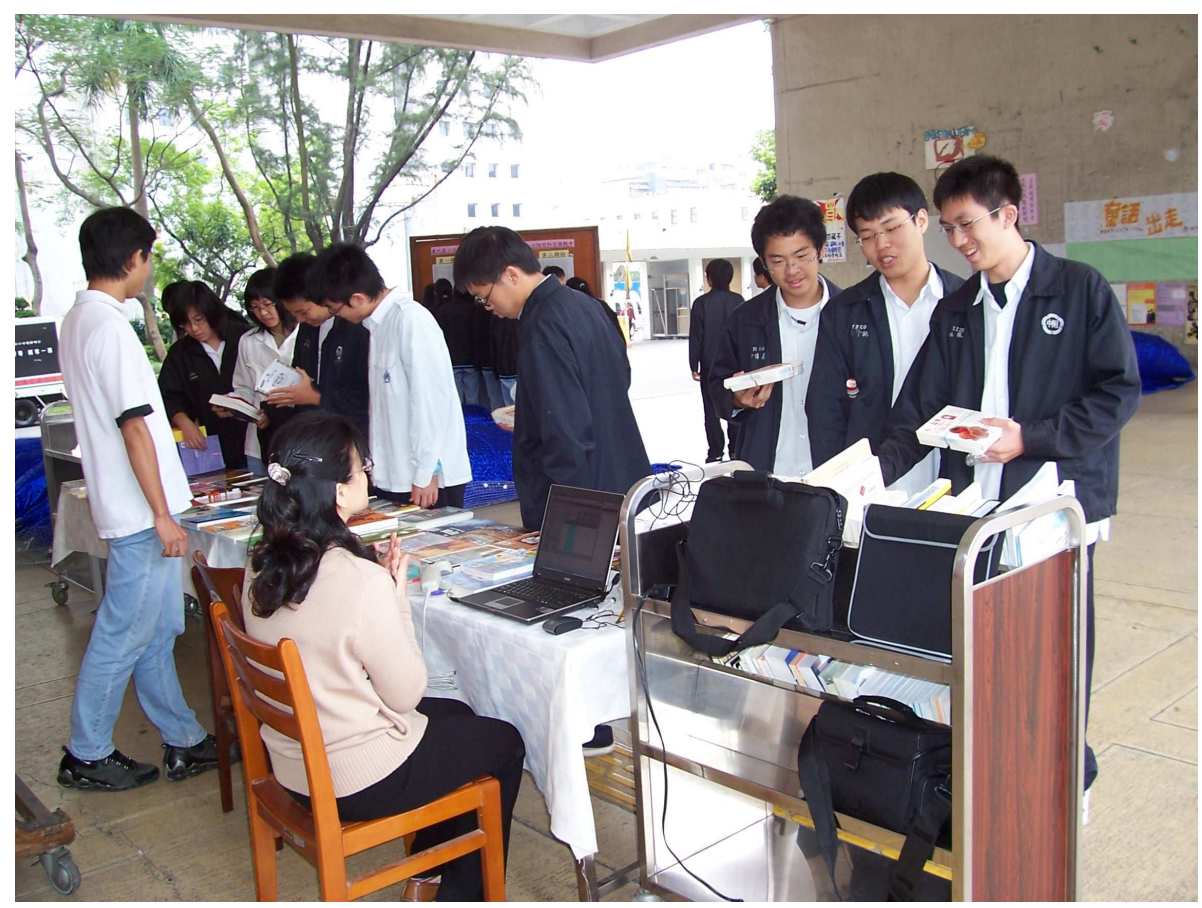


Picture 3: The library holds the "New book lending promotion program" activity and everyone is happy.

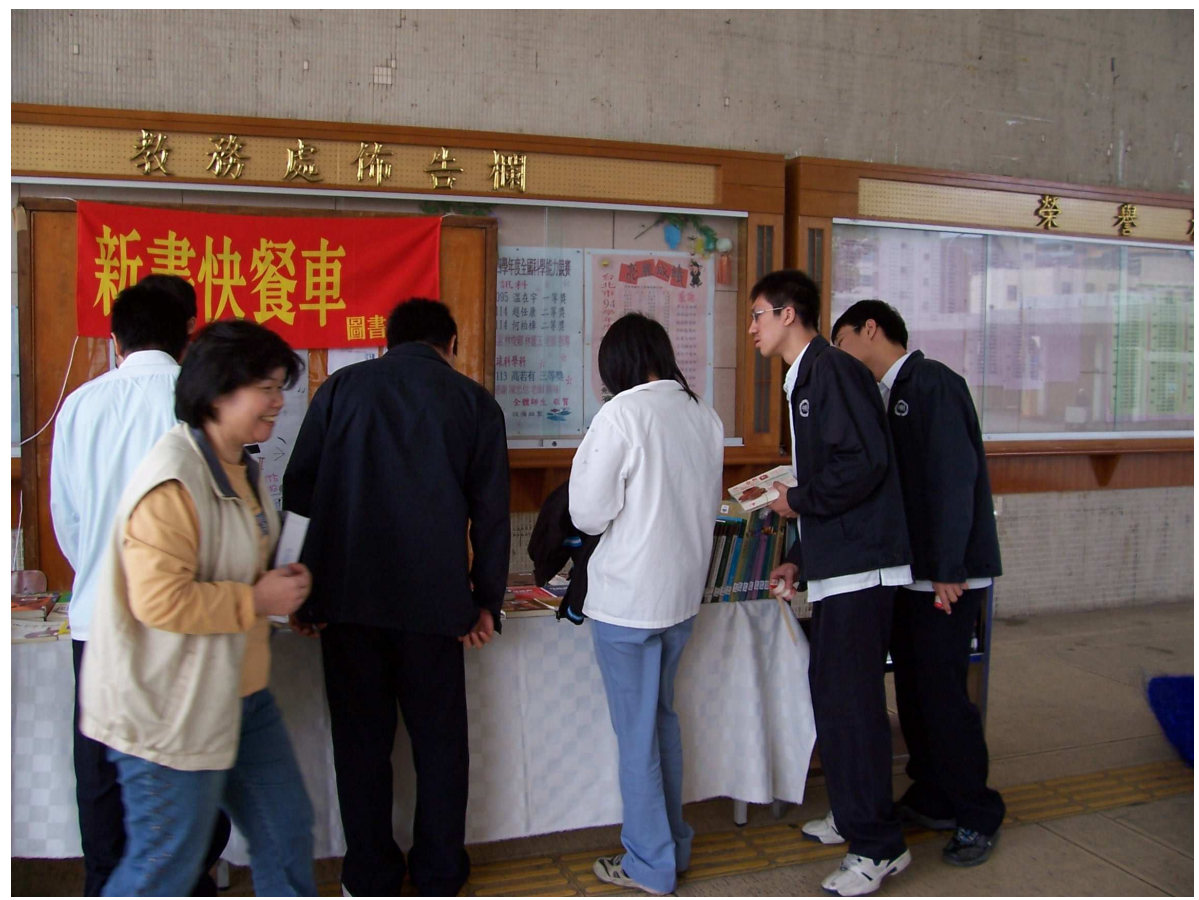

Picture 4: We prepare hot coffee for teachers but not for students. Because they are too young to drink caffeine drinks.

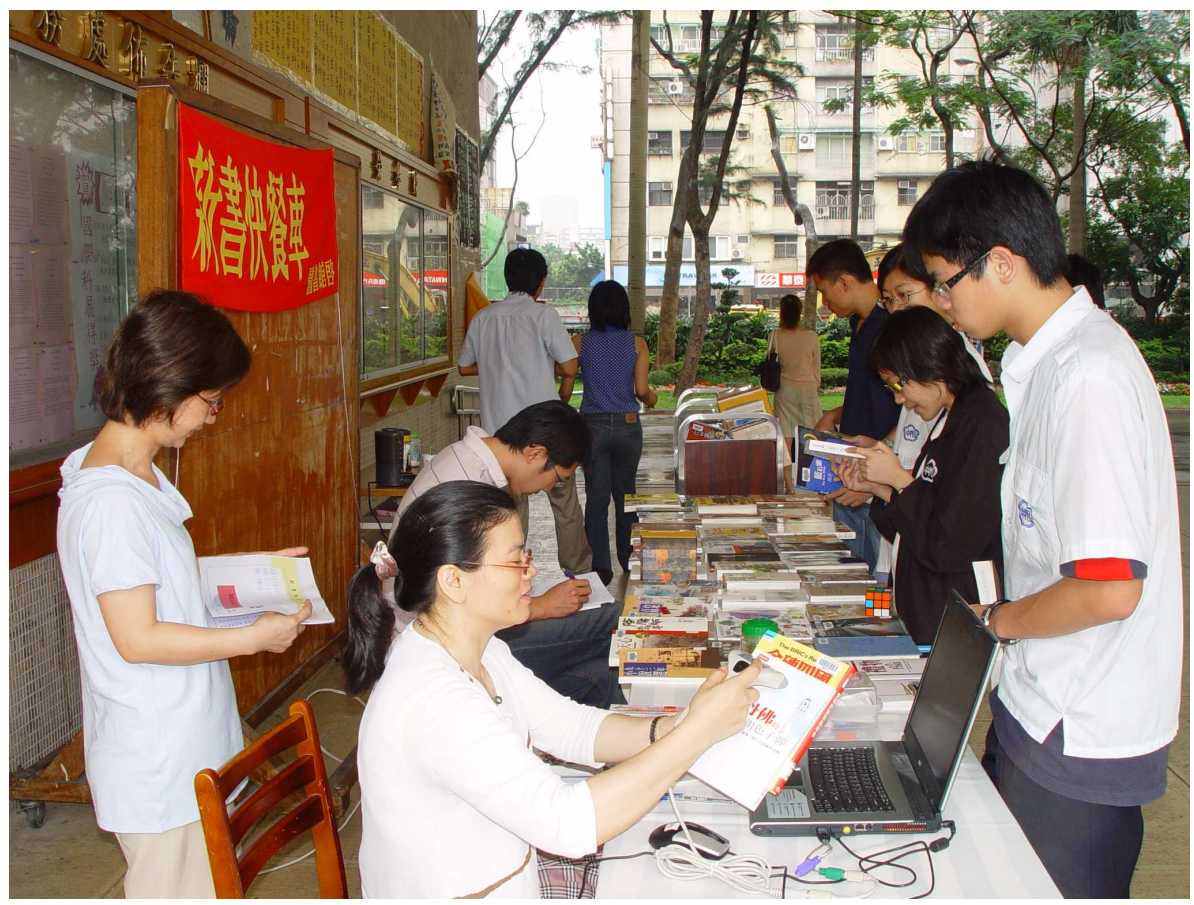


Picture 5: Location is important! We choose a very good location that is near the school entrance and restaurant.

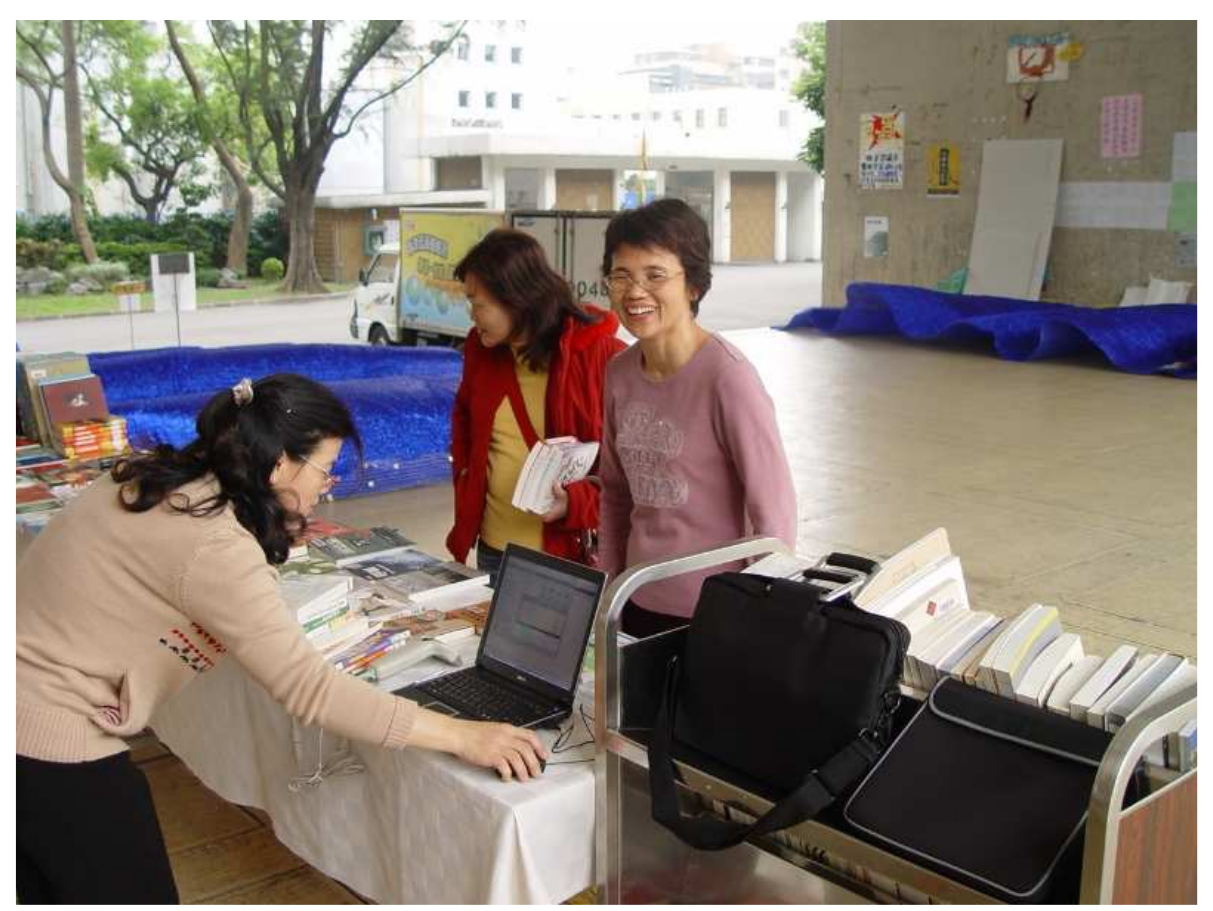

Picture 6: We use information technology to support our service. The information technologies are including notebook, barcode reader, and wireless environment.

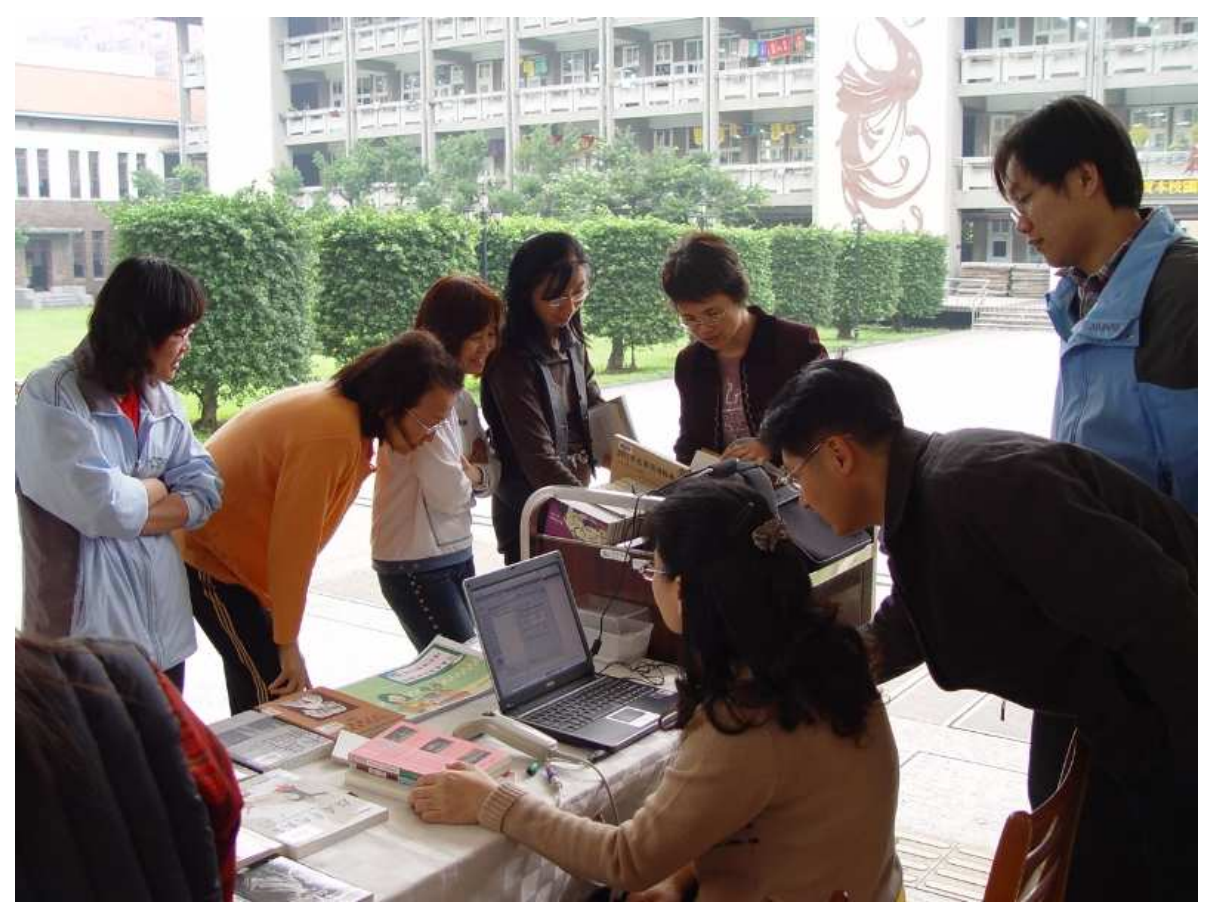


Picture 7: So many teachers and students enjoy the activity. They are so happy to borrow some new books through our new proactive service.

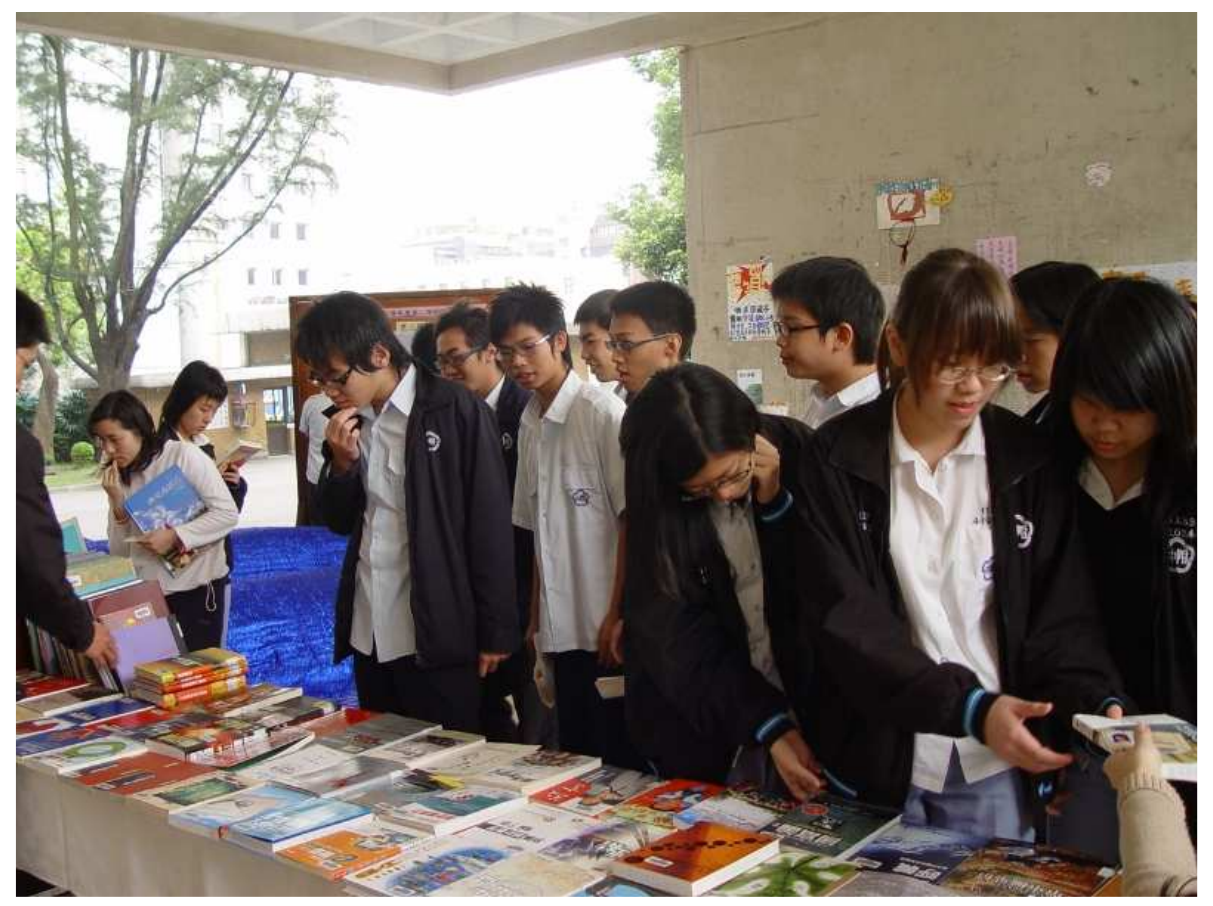

Results and Discussion

The latest arrival books were sorted into volumes and displayed in the activity spots. A total of 303 volumes of books were displayed in the "New book lending promotion program" activity, in which 129 volumes were the new books purchased by the library while 174 volumes were the ones given by the central office of MOE.

We hold the New book lending promotion program two days with a total of 303 books. After the "New book lending promotion program" activity, 111 of the new books purchased by the Library were borrowed with 18 left at the rate of $86 \%$; 64 of the books given by central office of MOE were borrowed with 110 left at the rate of $37 \%$. Overall, 175 books of the total 303 books were borrowed at the rate of $58 \%$.

This activity effectively enlivens the functions of the Library and the new books were brought to readers in active marketing, solving the problem of low borrowing rate of new books in the past (only $20 \%$ of new books were borrowed a year). As being closer to the needs of teachers and students at the School, the books purchased by the library enjoy a rate of $86 \%$, which is indeed impressive.

The activities effectively brings new books to the teachers and students and enhances the service image of the Library, making teachers and students more fond of reading and get close to the Library.

This paper thoroughly introduces the promotion process and implementation effect. In addition, the acceptance levels of the new books from different sources are also investigated. The borrowing rate of the new books purchased by the library is higher than the new books given by the central office of MOE. 
In the end, it hopes that the results will be provided as the reference for all promotion activities, and such proactive services as well as aggressive marketing model will be promoted to the campuses.

\section{Author Note:}

Lee, Chi-Lung, Director of Information Center at the Affiliated Senior High School of National Taiwan Normal University, has published two SSCI journal papers and presented papers at the international levels. He has two master degrees. One is Information and Computer Education at National Taiwan Normal University and the other is Business and Management at National Chiao Tung University. His major interest lies in developing information systems just like web-based learning system or knowledge management system that contribute to students learning and school administration. 